\title{
REARRANGEMENTS AND JENSEN TYPE INEQUALITIES RELATED TO CONVEXITY, SUPERQUADRACITY, STRONG CONVEXITY AND 1-QUASICONVEXITY
}

\section{S. ABRAMOVICH AND L.-E. PERSSON}

Abstract. In this paper we derive and discuss some new theorems related to all rearrangements of a given set in $\mathbb{R}^{n}$, denoted $(\mathbf{x})$ and use the results to prove some new Jensen type inequalities for convex, superquadratic, strongly convex and 1 -quasiconvex functions.

Mathematics subject classification (2010): 26D15, 26A51.

Keywords and phrases: Inequalities, Jensen's inequality, rearrangements, circular rearrangements, convexity, superquadracity, strong convexity, 1 -quasiconvexity.

\section{REFERENCES}

[1] S. ABRAmOvich, The increase of sums and products dependent on $\left(y_{1}, \ldots, y_{n}\right)$ by rearrangement of this set, Israel J. Math., 5,(1967), 177-181.

[2] S. Abramovich, Superquadracity of functions and rearrangements of sets, J. Inequal. Pure and Appl. Math, 8(2), Art.46, (2007).

[3] S. Abramovich, G. Jameson, and G. Sinnamon, Refining Jensen's inequality, Bull. Math. Soc. Sci. Math. Roumanie (N.S.) 47(95) (2004), no.1-2, 3-14.

[4] S. Abramovich AND L-E. Persson, Fejer and Hermite-Hadamard inequality for $N$-quasiconvex functions, Math. Notes, 102 (5), (2017), 644-656.

[5] A. L. Lehman, Results on rearrangements, Israel J. Math., 1, no.1, (1963), 22-28.

[6] C. P. Niculescu AND L.-E. Persson, Convex functions and their applications - A contemporary approach, Second Edition, Canad. Math. Series Books in Mathematics, Springer, (2018).

[7] J. PeČarić, F. Proschan And Y. L. Tong, Convex functions, partial ordering and statistical applications, Mathematics in Science and Engineering, 187, Academic Press Boston, (1992).

[8] H. Yu, Circular rearrangement inequality, J. Math. Inequal, 12, (2018), no.1, 636-643. 